\title{
Sugestão para uma Actividade Prática de Laboratório SOBRE OXIDAÇÃO-REDUÇÃO
}

\author{
Mário Valente* e Helena Moreira
}

O programa da disciplina de Física e Química A - nivel 2 refere o estudo dos processos de oxidação-redução de uma forma qualitativa. No presente artigo propõe-se a realização de um trabalho prático simples mas bastante didatico. Note-se que este trabalho prático pode ser efectuado com meios rudimentares, em qualquer laboratório escolar.

\section{INTRODUÇÃO}

No ponto 2.3. (Chuva ácida) da componente de química do programa da disciplina de Física e Química A - nível 2 [1] vem referido o estudo qualitativo dos processos de oxidação-redução. A actividade laboratorial aqui proposta incide particularmente sobre os seguintes pontos do referido programa:

- "Caracterizar o impacto dos ácidos sobre alguns metais como uma reacção de oxidação-redução onde um dos produtos é o hidrogénio gasoso",

- "Interpretar uma reacção de oxidação-redução em termos de transferência de electrões",

- "Reconhecer que a oxidação envolve cedência de electrões e que a redução envolve ganho de electrões",

- "Associar a ocorrência de uma reacção ácido - metal à possibilidade do metal se oxidar com redução simultânea do ião hidrogénio".

Esta actividade prática de laboratório consiste numa sequência de três experiências nas quais os alunos poderão verificar vários processos de oxidação-redução e relacionar os poderes redutores e poderes oxidantes das várias espécies intervenientes.

Antes de mais convém relembrar aos alunos que no decurso de um processo de oxidação-redução ocorrem trocas de electrões entre duas espécies, e que a perda de electrões se denomina oxidação, e o ganho de electrões se denomina redução. Uma

\footnotetext{
Colégio D. Duarte, Rua Visconde de Setúbal, 86, madmage1@yahoo.com
}

espécie que perca electrões, isto é, que se oxide, denomina-se agente redutor (pois cede electrões a outra, reduzindo-a) e uma espécie que ganhe electrões, isto é, que se reduza, é denominada de agente oxidante (pois captura electrões de outra espécie, oxidando-a). Assim, sempre que ocorra uma oxidação, ocorrerá também uma redução, e vice-versa.

Em duas das experiências faz-se uso de di-hidrogénio (ou hidrogénio molecular). Este é um gás que forma muito facilmente misturas extremamente explosivas com o ar e a obediência às regras de segurança é, por isso, de grande importância (ver nota de segurança).

\section{EXPERIÊNCIA 1:}

A REACÇÃo ENTRE O FERRO E O ÁcIDO SULFÚRICO

Num balão de kitasato, com um tubo de borracha de cerca de $50 \mathrm{~cm}$ de comprimento fixo na tubuladura lateral, coloca-se cerca de $2 \mathrm{~g}$ de lã de aço (fina) e $20 \mathrm{ml}$ de água. Adicionam-se, de seguida, ao conteúdo do balão, $50 \mathrm{ml}$ de uma solução de ácido sulfúrico em água (1:1 em volume ver nota de segurança). Com uma rolha de borracha tapa-se a boca do balão de kitasato.

A reacção entre o ácido sulfúrico e o ferro, traduzida pela equação

$\mathrm{H}_{2} \mathrm{SO}_{4}(\mathrm{aq})+\mathrm{Fe}(\mathrm{s}) \rightarrow \mathrm{FeSO}_{4}(\mathrm{aq})+$

$$
\mathrm{H}_{2} \text { (g) (1) }
$$

é rápida, devido à grande superfície reaccional proporcionada pela lã de aço, sendo muito nítida a libertação de di-hidrogénio.

Para reconhecer a presença de di-hi- drogénio enche-se um tubo de ensaio com o gás que sai pela extremidade livre do tubo de borracha (a recolha deve ser feita com o tubo de ensaio invertido). Após cerca de 10 a 20 segundos retira-se o tubo de ensaio (que é sempre mantido invertido) e, a uma distância de pelo menos um metro da montagem, aproxima-se da sua boca a chama de um fósforo. Observar-se-à a ocorrência de um rápido silvo ou uma pequena explosão, conforme o tubo esteja cheio de di-hidrogénio ou contenha ainda um pouco de ar. A combustão do di-hidrogénio no ar é traduzida pela equação:

$2 \mathrm{H}_{2}(\mathrm{~g})+\mathrm{O}_{2}(\mathrm{~g}) \rightarrow 2 \mathrm{H}_{2} \mathrm{O}(\mathrm{g})$

e é extremamente exoenergética.

\section{EXPERIÊNCIA 2:}

A REDUÇão do ÓXIDO DE COBRE (II) PELO DI-HIDROGÉNIO

Fixa-se à extremidade live do tubo de borracha da montagem anterior um tubo de vidro resistente com um comprimento de aproximadamente $20 \mathrm{~cm}$, que trespassa uma rolha de borracha para poder ser facilmente fixo num suporte universal (Figura 1).

A meio desse tubo de vidro coloca-se uma pequena quantidade de óxido de cobre (II) tendo o cuidado de evitar que ocupe toda a secção do tubo, entupindo-o.

Por fim, fixa-se outro tubo de borracha, de pelo menos $50 \mathrm{~cm}$ de comprimento, à extremidade livre do tubo de vidro.

A montagem final encontra-se representada na Figura 1. 


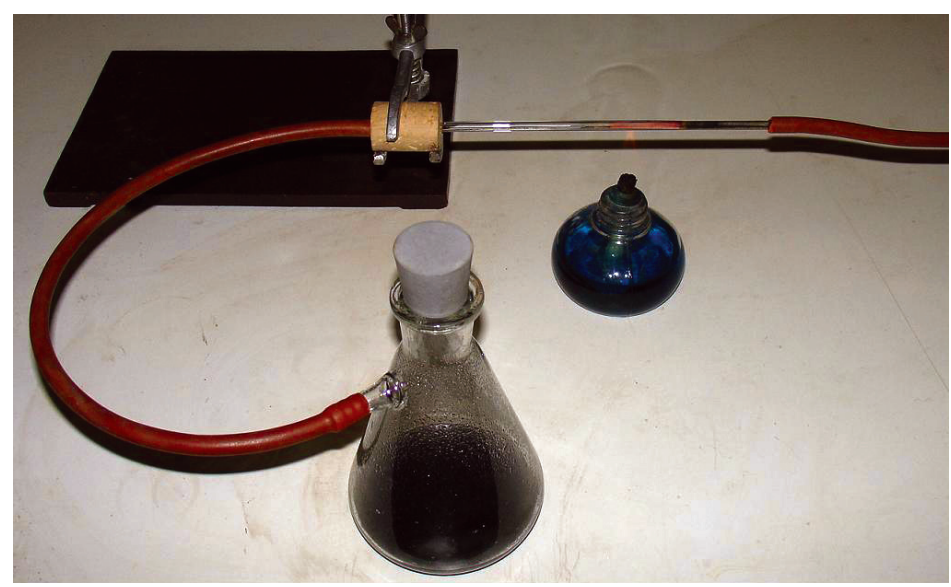

Figura 1 Montagem para a preparação de di-hidrogénio e redução de óxido de cobre (II)

Poderá, agora, ser aconselhável adicionar mais lã de aço ao conteúdo do balão de kitasato, caso a formação de di-hidrogénio seja lenta ou tenha cessado por completo.

Para que a redução do óxido de cobre (II) se inicie é necessário um aquecimento inicial deste, que pode ser conseguido, por exemplo, com a chama de uma lamparina a álcool. Assim que o processo se inicie, o que se verifica pelo aparecimento de um ponto ao rubro (Figura 2), pode-se remover a lamparina já que a reacção é suficientemente exoenergética para se manter por si própria. A reacção observada pode ser traduzida pela equação

$\mathrm{CuO}(\mathrm{s})+\mathrm{H}_{2}(\mathrm{~g}) \rightarrow \mathrm{Cu}(\mathrm{s})+\mathrm{H}_{2} \mathrm{O}(\mathrm{g})$

A formação de água pode ser confirmada pela observação de condensação nas partes frias do tubo de vidro, a jusante do local da reacção (Figura 2).

\section{EXPERIÊNCIA 3:} DE COBRE (II) equação:
A REACÇÃO ENTRE O FERRO E O SULFATO

Num tubo de ensaio contendo uma solução de sulfato de cobre (II) coloca-se alguma lã de aço, observando-se a rápida formação de cobre metálico, de cor característica, à sua superfície, de acordo com a

$$
\begin{array}{r}
\mathrm{CuSO}_{4}(\mathrm{aq})+\mathrm{Fe}(\mathrm{s}) \rightarrow \underset{\mathrm{FeSO}}{\mathrm{Cu}_{4}(\mathrm{~s})}(\text { (4) } \\
\end{array}
$$

Se a lã de aço for suficiente para reagir com todo o ião cobre, a cor da solução passará de azul, cor característica do ião cobre (II) em solução aquosa, para verde claro (Figura 3, tubo da direita), cor característica do ião ferro (II) em solução aquosa.

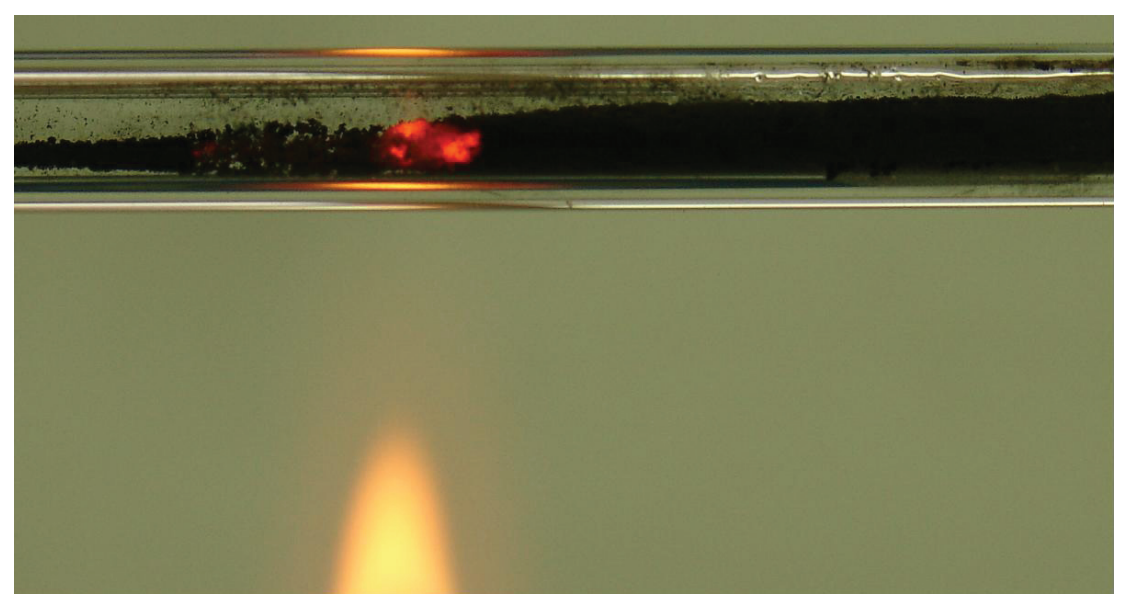

Figura 2 Pormenor do tubo de vidro onde se pode observar a redução (exoenergética) de óxido de cobre (II) a cobre metálico

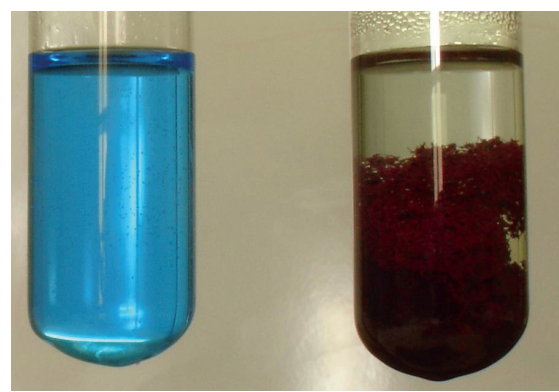

Figura 3 Tubos de ensaio contendo, à esquerda, (III) (I) éćs ásito solução de sulfato de ferro (II) e um depósito de cobre metálico

\section{Discussão}

Todos os processos químicos realizados nesta sequência de experiências são de oxidação-redução. Assim, para a reacção de ferro com o ácido sulfúrico (ou mais propriamente com o $\mathrm{H}^{+}$originado pela ionização deste em água), a equação 1 pode ser reescrita de forma a apresentar apenas as espécies directamente envolvidas, isto é:

$2 \mathrm{H}^{+}+\mathrm{Fe} \rightarrow \mathrm{Fe}^{2+}+\mathrm{H}_{2}$

Nesta equação pode-se observar que dois catiões hidrogénio ao serem convertidos em di-hidrogénio - uma redução - capturam os dois electrões que são libertados pelo ferro ao ser convertido em catião ferro (II) - uma oxidação. Como resultado, os alunos podem concluir que o catião hidrogénio é um oxidante mais poderoso que o catião ferro (II) e, portanto, que o di-hidrogénio é um redutor mais fraco que o ferro.

$\mathrm{Na}$ descrição da experiência da redução do óxido de cobre (II) a equação 3 também pode ser reescrita apresentando apenas as espécies intervenientes, segundo:

$\mathrm{Cu}^{2+}+\mathrm{H}_{2} \rightarrow \mathrm{Cu}+2 \mathrm{H}^{+}$

O catião cobre (II) captura dois electrões convertendo-se em cobre metálico. Os dois electrões são cedidos pelo di-hidrogénio que é convertido em dois catiões hidrogénio, que rapidamente se ligam ao anião óxido (do óxido de cobre) para formar água

Note-se que a água não é uma substância iónica: o ião óxido partilha um par de electrões de valência com cada catião hidrogénio. 
Desta experiência os alunos podem concluir que o di-hidrogénio é um redutor mais poderoso que o cobre e, portanto, que o catião hidrogénio é um oxidante mais fraco que o catião cobre (II).

Para a terceira experiência, a equação 4 também pode ser reescrita apresentando apenas as espécies intervenientes, segundo:

$\mathrm{Cu}^{2+}+\mathrm{Fe} \rightarrow \mathrm{Cu}+\mathrm{Fe}^{2+}$

Neste processo o catião cobre (II) captura dois electrões convertendo-se em cobre metálico. Os dois electrões são cedidos pelo ferro que é convertido em catião ferro (II), de onde os alunos poderão concluir que o ferro é um redutor mais poderoso que o cobre e, portanto, que o catião ferro (II) é um oxidante mais fraco que o catião cobre (II).

Após análise dos resultados os alunos podem facilmente estabelecer séries comparativas de poderes redutores $\left(\mathrm{Cu}<\mathrm{H}_{2}<\mathrm{Fe}\right)$ e de poderes oxidantes $\left(\mathrm{Fe}^{2+}<\mathrm{H}^{+}<\mathrm{Cu}^{2+}\right)$.

\section{Questões / Desafios}

De seguida sugerem-se algumas questões pertinentes que testam o poder de observação e a capacidade de relacionar e operacionalizar conceitos, por parte dos alunos.

- Por que razão se recolheu o di-hidrogénio num tubo de ensaio invertido?

- Será que se pode obter ferro metálico da mesma forma que se obteve o cobre metálico?

- Será que o cobre reage com ácidos diluídos?

- A solução resultante da reacção entre a lã de aço com ácido sulfúrico é também verde clara mas observa-se a presença de uma substância negra em suspensão. O que poderá ser (investigue-se a composição do aço)?

\section{Conclusão}

Consideramos a presente sequência de experiências bastante enriquecedora, já que permite aos alunos observar a ocorrência de vários processos de oxidação-redução que estão interligados, pois envolvem essencialmente três elementos: o cobre, o hidrogénio e o ferro. Como resultado, é-lhes possível estabelecer comparações entre os resultados das várias experiências e chegar a conclusões que possuem poder preditivo.

\section{Notas de Segurança}

A primeira experiência envolve a utilização de uma solução aquosa (1:1 em volume) de ácido sulfúrico. Essa solução é preparada adicionando o ácido concentrado, em pequenas quantidades, à água. $\mathrm{A}$ adição deve ser acompanhada de uma agitação eficaz de modo a dissipar o calor gerado aquando da dissolução. Devido aos perigos inerentes, esta solução deverá ser preparada pelo professor. Duas das três experiências propostas envolvem di-hidrogénio, que é um gás que forma muito facilmente misturas explosivas com o ar, pelo que se deverá ter o cuidado acrescido de nunca permitir a presença de chamas na proximidade $(\sim 1 \mathrm{~m})$ do aparelho onde o di-hidrogénio é gerado.

No decurso das experiências a utilização de batas e óculos de segurança é obrigatória.

\section{REFERÊNCIA}

[1] Programa da disciplina de Física e Química A (nível 2) $11^{\circ}$ ou $12^{\circ}$ anos:

http://www.dgidc.min-edu.pt/programs/prog_eg.asp

\section{Curiosidades - Energia Fotovoltaica}

No dia 2 de Junho, o gigante alemão Bosch anunciou que vai comprar $50,45 \%$ da companhia alemã de energia solar Ersol. A Bosch vai investir mais de 546 milhões de euros na primeira operação de aquisição de uma empresa produtora de células solares por um grande grupo. A Alemanha é o país com mais capacidade fotovoltaica instalada. A Ersol produz células de silício cristalino e de silício microcristalino em filme fino e é, a par das suas congéneres alemãs Conergy e Q-Cells, uma das maiores companhias de produção de células fotovoltaicas com um volume de vendas que em 2008 se prevê ser na ordem dos 300 milhões de euros. O anúncio da Bosch surgiu uns dias antes do início da maior feira de energia solar a nível mundial, a Intersolar, que teve lugar de 10 a 14 de Junho em Munique e menos de uma semana depois de a Q-Cells ter anunciado que vai investir cerca de 3,5 mil milhões de euros numa unidade de produção no México, destinada a fornecer o mercado norte-americano e a América Latina. As previsões indicam que a primeira fase do projecto, que produzirá células de filme filme, estará finalizada em 2009. A Conergy anunciou igualmente uma restruturação da empresa que passou pela venda das suas subsidiárias consideradas não estratégicas, como sejam as destinadas à produção de células solares para aquecimento. A restruturação da empresa tem como objectivo a dedicação exclusiva à produção de energias alternativas, com especial ênfase na energia fotovoltaica mas igualmente na produção de turbinas eólicas.

O investimento massivo no sector da energia fotovoltaica, de que o anúncio da Q-Cells é apenas um exemplo, resultará num drástico aumento da capacidade produzida, que passará dos cerca de 3 gigaW em 2007 para 15-20 gigaW em 2010. Os analistas preveêm, em consequência, que os preços das células fotovoltaicas irão cair num futuro próximo o que aumentará a competitividade desta energia alternativa. 


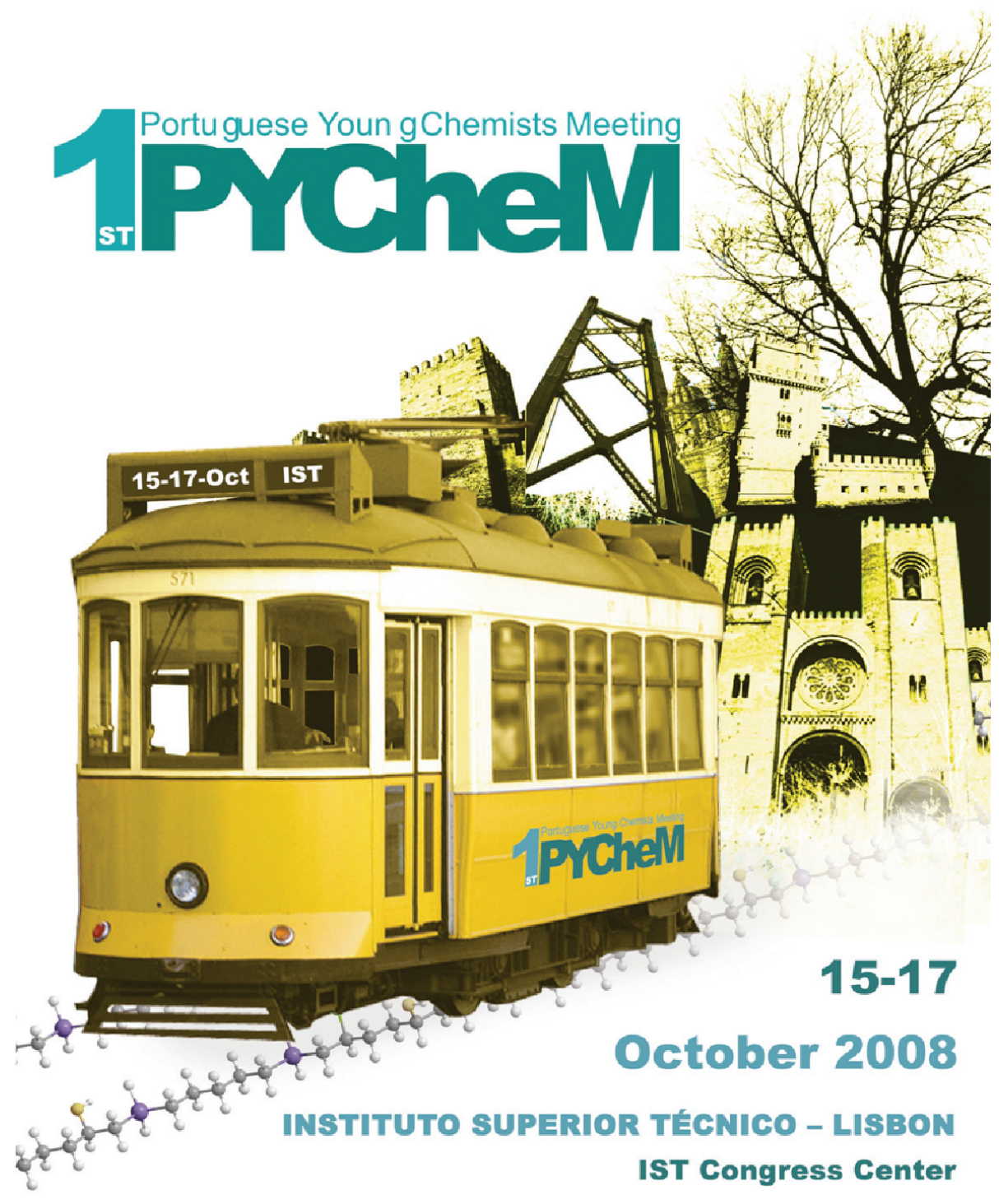

O $1^{\text {st }}$ Portuguese Young Chemists Meeting ( $\left.1^{\text {stPYCheM}}\right)$, organizado pelo Grupo de Químicos Jovens (GQJ) da Sociedade Portuguesa de Química (SPQ) terá lugar no Instituto Superior Técnico em Lisboa, entre 15 e 17 de Outubro de 2008.

Este encontro será um espaço privilegiado onde os jovens investigadores que se encontram em Portugal ou no estrangeiro, podem apresentar prioritariamente os seus trabalhos, conhecer o trabalho dos nossos colegas, discutir problemas e talvez criar ideias novas e colaborações futuras.

Teremos vários formatos de apresentação: comunicações orais, comunicações orais flash e posters. E a submissão de resumos já se encontra aberta.

O encontro contará ainda com 4 lições plenárias sobre temas transversais às diversas áreas da química.

Os oradores das plenárias serão:

- Carlos Romão (Instituto de Tecnologia Química e Biológica / Universidade Nova de Lisboa): "Coordination Chemistry: Trends and Challenges"

- João Pedro Conde (Departamento de Engenharia Química e Biológica / Instituto Superior Técnico): "Top-down nanotechnology: how to sculpt a nano-object"

- João Rocha (Departamento de Química-CICECO / Universidade de Aveiro): "New Light-Emitting Zeolites and Metal Organic Frameworks"

- Stephen Caddick (Departamento de Química / University College London): "Synthetic Chemistry: Un- derpinning Science for Biology and Medicine"

A juntar a este programa científico, teremos uma visita ao Museu da Ciência e o jantar do congresso, onde poderemos rever antigos colegas e amigos. Adicionalmente, teremos um espaço no programa do encontro dedicado exclusivamente a discutir os planos do Grupo de Químicos Jovens para o futuro.

Contamos com a vossa PResença

E-mail: 1pychem@spq.pt URL: www.spq.pt/gqj/1pychem 


\section{EYCN}

\section{European Young Chemists Network}

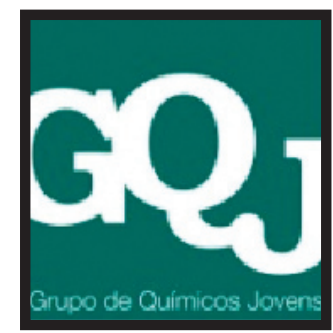

A European Young Chemists Network (EYCN) escolheu a Alemanha para realizar no próximo ano o seu primeiro congresso, para o qual estão desde já convidados todos os jovens químicos portugueses.

A EYNC, criada a 1 de Abril de 2007 em Berlim, faz parte da European Association for Chemical and Molecular Sciencies (EuCheMS). Os diversos países são representados por delegados das várias sociedades nacionais.

O Grupo de Químicos Jovens (GQJ) da SPQ tem como parte da sua missão assegurar essa representação, pelo que participou na primeira reunião anual de delegados que decorreu em Madrid a 19 de Março de 2008.

Nessa reunião fez-se um balanço do primeiro ano de actividades da rede, que consistiu na formalização desta organização e definição do seu âmbito de acção como parte da EuCheMS.

Assim, a EYNC tem como objectivo a criação de uma plataforma dentro da rede EuCheMS onde os jovens quími- cos possam:

1. Gerar uma opinião estruturada a nível europeu sobre ciência, educação e política em áreas afins à química;

2. Discutir interesses comuns, criar e expandir novas iniciativas que contribuirão de uma forma construtiva para o futuro da ciência e de uma forma mais geral para o desenvolvimento da sociedade europeia;

3. Formar uma rede de contactos que seja a génese de uma comunidade activa de jovens químicos na Europa;

4. Estabelecer novos laços entre a comunidade académica e a indústria.

Parte substancial da reunião de Madrid foi dedicada à apresentação das actividades dirigidas aos químicos jovens desenvolvidas e planeadas pelas várias Sociedades Químicas nacionais.

Na apresentação do GQJ da SPQ foi dada particular ênfase à realização do seu primeiro congresso em Outubro

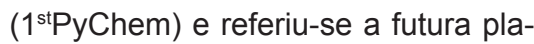

nificação de actividades de divulgação da Química ao nível das escolas, bem como o desenvolvimento de bolsa de emprego e incentivo ao empreendedorismo.

Estas últimas duas ideias foram particularmente elogiadas pelos restantes delegados e direcção da EYCN.

Por fim, e considerando que a etapa de implementação da EYCN se encontra na sua fase final, foi discutida a forma de abrir a rede a todos os jovens químicos europeus.

Acções como a criação de um sítio na internet (www.eycn.eu), a atribuição de prémios para jovens químicos, a criação de uma newsletter ou a divulgação das actividades da rede através dos representantes nacionais foram identificadas como essenciais para atingir esse objectivo.

O primeiro congresso a decorrer na Alemanha é parte essencial dessa estratégia.

Pedro M. P. Góis

\section{LivRos ReCENTEMENTE EdiTAdos}

Foi recentemente publicado pela Royal Society of Chemistry o livro "Creating Networks in Chemistry: The Founding and Early History of Chemical Societies in Europe".

Editado por Anita Kildebæk Nielsen e Sona Strbanova (Editoras), este livro tem por objecto de estudo o processo de criação e desenvolvimento das Sociedades Europeias de Química.

Apresenta, recorrendo a material histório único, as circunstâncias sociais, intelectuais e políticas em que as diversas sociedades foram criadas e de que forma condicionaram o seu funcionamento.
Contou com a colaboração de membros do Grupo de História e com o apoio da SPQ.

Pode obter mais informação em: http://www.rsc.org/Shop/ books/2008/9780854042791.asp. 


\section{Actualidades Científicas}

\section{SUPERISOLANTE}

Os supercondutores, materiais que em determinadas condições apresentam resistência eléctrica nula e que por essa razão são teoricamente capazes de sustentar indefinidamente uma corrente eléctrica sem qualquer fonte de tensão externa, são materiais já conhecidos há décadas. No entanto, os seus materiais opostos, os superisolantes, eram totalmente desconhecidos até agora. Um material deste tipo, que apresenta propriedades eléctricas contrárias aos supercondutores, ou seja, resistência eléctrica extremamente elevada a temperaturas próximas do zero absoluto em relação ao seu valor à temperatura ambiente (100000 vezes superior, neste caso), foi apresentado recentemente por uma equipa de investigadores.

Valerii Vinokur, do Argonne National Laboratory e a sua colega Tatyana Baturina, juntamente com outros cien- tistas de Argonne e colaboradores da Bélgica, Alemanha e Rússia, prepararam um filme muito fino de nitreto de titânio de forma a obterem um material com características superisolantes. A teoria aceite que explica a supercondutividade, aplicável neste caso ao nitreto de titânio, baseia-se no conceito de par de Cooper. Assim, nos supercondutores, abaixo de determinados valores de temperatura e de campo magnético aplicado (designados por temperatura crítica e por campo crítico), os electrões organizam-se em pares, movimentando-se praticamente sem restrições, reduzindo a resistência a um fluxo de corrente eléctrica até valores praticamente nulos. Vinokur explica que os filmes de nitreto de titânio, tais como de outros materiais, podem comportar-se não como supercondutores mas sim como superisolantes se a sua espessura for suficientemente fina. No caso de um filme muito fino de nitreto de titânio, abaixo da temperatura crítica e campo crítico, os electrões originam pares de Cooper, mas estes não se podem movimentar, originando um estado com uma resistência eléctrica teoricamente infinita.

Tal como os supercondutores, que têm vasta aplicação em equipamentos tecnológicos (como aceleradores de partículas, espectrómetros, comboios de levitação magnética, etc), os superisolantes podem também ser aplicados na protecção de todos os tipos de circuitos eléctricos e electrónicos, sensores e baterias (de forma a evitar descargas prematuras ou curto circuitos). A encapsulação de um fio supercondutor com um material superisolante criaria um dispositivo eléctrico virtualmente perfeito com perdas de energia por calor praticamente nulas. Versões miniaturizadas destes fios supercondutores superisolados poderiam conduzir ao desenvolvimento de circuitos eléctricos de maior eficiência. (adaptado de webzine Reactive Reports 73, 2008).

Paulo Brito

\section{Actualidades Científicas}

\section{URÂNIO ORGÂNICO}

A primeira molécula de metino de urânio (uranium trifluoride methylidyne) foi sintetizada por químicos norte-americanos. Esta nova estrutura contém uma ligação tripla urânio-carbono, detectada pela primeira vez. Um metino é um grupo funcional trivalente $\mathrm{CH}$, em que, além da ligação simples ao átomo de hidrogénio, o carbono pode ainda estabelecer uma ligação tripla.

Lester Andrews da University of Virginia e os seus colaboradores trabaIham no campo da química do urânio há quinze anos, tendo sintetizado dúzias de moléculas diferentes.

Assim, o seu conhecimento da reactividade do urânio é bastante extenso. Para obter este último composto, necessitaram de recorrer a um laser pulsado para evaporar urânio empobrecido numa câmara de vácuo, que reagiram com fluorofórmio (ou trifluormetano, $\mathrm{CHF}_{3}$ ).

Posteriormente, usaram uma atmosfera de argon a $8 \mathrm{~K}$ para fixar as moléculas do novo composto. Andrews explica que o átomo de urânio introduz-se numa ligação carbono-flúor, rearranjando os restantes átomos de flúor de forma a se obter uma nova estrutura. De seguida, a equipa usou espectroscopia de infra-vermelho para caracterizar esta exótica e instável ligação tripla urânio-carbono.

Através da espectroscopia de infra-vermelho, a equipa estimou a estrutura e as propriedades de ligação do novo composto e comparou a simulação com os resultados espectroscópicos, tendo concluído que o ajuste era suficientemente bom para confirmar a obtenção da estrutura pretendida.

Adicionalmente, Andrews acrescenta que as propriedades dos compostos de urânio não deveriam interessar apenas aos químicos, mas também aos próprios políticos.

Assim, na sua opinião, sabendo-se da necessidade de submeter o minério de urânio a processos químicos bastante complexos para que este possa ser aplicável como material nuclear, tal torna imperativo um melhor conhecimento da sua química. (adaptado de webzine Reactive Reports 70, 2007).

Paulo Brito 